\title{
Community Language Teaching to Bilingual Learners. Towards a Systematic Approach to its Methodology and Curriculum
}

Arturo Tosi

\section{Introduction}

In this article I will not deal with the extensive literature on the many answered, and many other unanswered, questions in the area of language teaching, which have dictated the current criteria for foreign language evaluation and examination. Nor do I want to enter, or to open, the more recent, but fast developing debate on community language teaching and the rationales for the evaluation of both pupils' and teachers' skills. What I shall attempt to do, instead, is to examine the convergent as well as the divergent components which characterize these two processes of language learning and which may, of course, have implications in the area of evaluation of language competence.

Before dealing with these tasks, however, I propose to represent visually the interconnection of the variables characteristic of this particular learning process in an integrated structure; and in order to clarify this structure, comparison will be made with other structures representing, respectively:

1. monolingual development for monolingual learners

2. bilingual development for mono/bilingual learners

3. monolingual development for bi-dialectal learners

4. mother-tongue development in the context of secondlanguage learning

\section{Monolingual and bilingual language learning}

An ideal model describing a language-learning process is probably most easily thought of as similar to a multi-tiered cylinder (see fig. 1). The bottom layer contains variables relative to the lan- 
guage spoken in the home and in the immediate family environment: the middle layer contains factors relative to language infrastructure and sources of exposure in the community; and the top layer contains components of the school curriculum designed to develop its pupils' linguistic resources to meet the standard of language competence demanded by society.

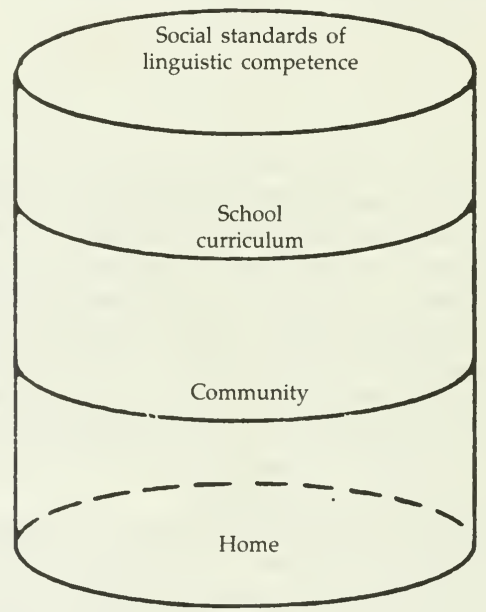

Fig. 1 Distribution of variables in a conventional language-learning model

The dimension of such standards is represented by the size of the top circle of the cylinder. Since the achievement of these standards is the goal of any linguistic education policy, it is clear that the greater the fulfilment of the volume of each of the three layers sustaining the top, the firmer the support given to the child's language development.

The four different learning processes mentioned above can be visualized as four cylinders associated in three cases with other shapes representing the different distribution of variables relevant to different monolingual and bilingual learning processes (Fig. 2). 


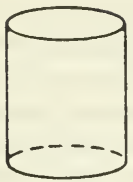

2a

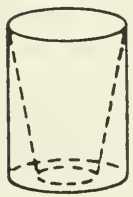

2c

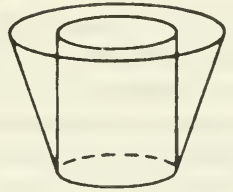

$2 b$

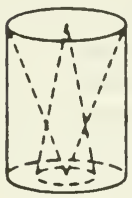

$2 \mathrm{~d}$

Fig. 2 The four language-learning processes

Figure $2 \mathrm{a}$ represents the typical situation of monolingual children from a family background where the standard language is spoken, and linguistic guidance and support is provided by the parents and the immediate circle of neighbours and peers. They are exposed to the same language in an environment rich in sources of exposure to selected and sophisticated patterns of linguistic interaction. The school's role is to reinforce and organize their language competence to meet the demands of the curriculum. Their overall monolingual development in the standard language is protected, and directed towards the achievement of the standards demanded by their monolingual school and society; standards that they are most likely to meet as a result of concomitant situations conveying their language development into a channel (the cylinder) which concentrates their efforts on the fulfilment of the academic and social goals created by that society.

Fig. $2 b$ represents the more privileged conditions of bilingual development for children from a solid mono/bilingual background, who benefit from bilingual education in the mothertongue with a high-status foreign/second language. Figure $2 b$ consists of a cylinder corresponding to the situation described in the previous section, where the base may or may not include a bilingual situation at home. As before, the same measures are taken to secure a solid linguistic development in the home, school and community main language, and in addition others are introduced to expand the child's academic and social opportunities. The 
volume enclosed between the cylinder and the truncated cone surrounding it represents the extra measures taken within the three adjoining sections to maintain and develop bilingualism at no detriment to a solid linguistic experience and education in the mother tongue. The linguistic standards demanded by society in one national/Standard language (also the pupil's mother tongue) are achieved (top circle), and at the same time there is a chance to achieve bilingualism in another high-status language (as represented by the wider circle of the truncated cone), and to be able to operate linguistically in a multi/international dimension.

Figure $2 \mathrm{c}$ represents the far more common situation of monolingual schooling for a child who lives in a bidialectal family and environment. The standards of linguistic competence demanded by society in the national language remain the same, as represented by the top circle, whilst the truncated cone enclosed in the cylinder represents the limited family/environmental support available to the child for the development of his/her competence in the Standard language. In particular, a limited family training in the Standard, poor sources of exposure to that language in the community and the inability of the school to cope effectively with bidialectal children (often resting on the principle that equal treatment means equal opportunity) all result in a dispersion of efforts (represented in Fig. $2 \mathrm{c}$ by the section of volume between the cylinder and truncated cone). This happens when the school and society value only competence in the Standard and disregard or even penalize any other dialect.

Figure $2 \mathrm{~d}$ represents the process identified as "mother tongue development in the context of second language learning," one typical of minority pupils learning their first language in a multiethnic society. The top circle representing the standards of linguistic competence necessary to achieve equal social opportunities, remains the same in a society with a multilingual population — but a monolingual policy — as in a society with a monolingual population (compare Fig. 2a). The achievement of such standards, however, becomes even more difficult for linguistically diverse children than in the situation described in Fig. 2c. In fact, their point of departure - the family support in relation to the majority (L2) language - is almost non-existent (which in Fig. 2d is represented by the apex of the inverted cone). Facilities for L2 development increase in the environment and the school, although they form a much poorer complex of environmental situations in comparison to those in the three other cases. The mother 
tongue, instead, starts from a more favourable position - as represented by the base of the other cone - although it might often be a rural or contact dialect of little use outside the community and stigmatized even in the homeland. Its development might originally benefit from the rich infrastructure within the family and neighbourhood, but in later life, not being reinforced by full conditions of exposure, the mother tongue might develop only within restricted domains. At school, with the exception of those countries which have adopted a bilingual education policy, the mother tongue might occupy a minimal portion of the timetable or even be confined outside the monolingual school. Overall, the time and resources needed to develop linguistic and academic skills in the mother tongue can be just as limited as the inclination of the majority society to maintain and value bilingualism in minority communities. The volume which represents the constraints of mother tongue development in the context of second-language learning (the latter component represented by the cone in the inverted position) takes the shape of a cone with the apex in the area of social demands for linguistic competence. At that level, competence in the minority language can be considered quite irrelevant with regard to social opportunities, and society's appreciation of bilingualism shrinks to become a small point in those countries which neither value nor encourage qualification and literacy in minority language.

A comparison between the two shapes representing two situation of bilingual development (including one form of bilingualism valued and another disdained by society) shows that, in the first case, the original cylinder is surrounded by additional volume, as in Fig. 2b, whilst in the other cylinder (Fig. 2d) a portion of volume has been subtracted. This accords with Lambert's distinction between "additive" and "subtractive" bilingualism. He says that in the first situation "the bilingual is adding another socially relevant language to his repertoire of skills at no cost to his L1 competence"; in the second, "the bilingual's competence in his two languages at any point is likely to reflect some stage in the "subtraction" of L1 and its replacement by L2." The latter case, Lambert further comments, is typical of "many ethnic minority groups who, because of national educational policies and social pressures of various sorts, are forced to put aside their ethnic language for a national language." As these speakers may be characterized by less than native-like competence in both languages, 
some recent studies have presented their conditions in terms of "double-semilingualism" or "semilingualism."

\section{Foreign language acquisition and community language learning}

In order to develop my arguments with relation to the variables which characterise, respectively, foreign language acquisition and community language learning, I shall focus on five crucial points which correspond to important assumptions which have proven relevant and effective in the practice of traditional foreign language acquisition. For each of them I shall discuss its relevance once we transplant it in the reality of community language learning. In particular I am interested in ascertaining their relevance and examining their implications at three levels:

1. the initial competence of the learners

2. the principles of course planning

3. the practices of teaching

\section{Learners' linguistic background.}

My first point concerns assumptions on the linguistic background of the learners. In the area of foreign language teaching the working assumption in connection with initial competence is that the learner has one language (the source language), and that he/she has a native command of it, whilst the other which is being studied as a foreign language, is totally alien to the pupil's monolingual experience: something which the professional jargon indicates as 0 beginner experience in relation to the new linguistic system. It is interesting that most difficulties or errors, in the process of learning it, can be predicted and mapped out at the three classic levels of phonetics, morphology and lexis.

However, if we take the question of the learner's linguistic background in the area of community language learning, the answer is quite different since, in fact, we cannot identify a single common pattern. As most teachers have experienced in community language learning the pupil's mother tongue (in the sense of the dominant language, not the language of the mother) is often linguistically and cognitively the second language. But this situation cannot be generalized. We can also find young people for whom the mother tongue is linguistically a first language, but not cognitively, or vice versa. Moreover these three patterns can vary in the same speaker according to age, birth of new siblings, the length of residence of the family, its level of assimilation within 
the minority community, and finally whether that community is linguistically or socially isolated or both. What I am really getting at is that the very large majority of learners of community languages have already a bilingual experience to whatever level their competence has developed and has become communicable in speaking and writing.

The implications of this assumption are crucial at the level of setting the principles of course planning. The identification of objectives for grammar teaching or the introduction of graded communicative functions, can be approached more or less formally by the foreign language course and material designer (often it also depends on the pupil's age), and it can be offered in a more or less structured manner, depending on the instructor's style and training. Yet, however one organises the course, the modern language curriculum in the average school remains for the traditional foreign language learner a monolingual experience. But this is not so for learners of community languages. However formal is the style of instruction, however un-structured by the teacher is the exposure to the target language in the classroom, the pupil's learning, both inside and outside the school, develops through a substantial bilingual experience: an experience which, although communicable to different degrees of language competence and confidence, largely involves interaction, cognition and emotion integrated to the functions of two different language systems.

If we move on to the level of practices of good instruction, I am aware that it is difficult to describe the implications of different pupils' background from 0 beginner level to examination standards, without having agreed, beforehand, what is good instruction in modern language teaching.

$\begin{array}{lll}\text { LEARNERS' } & \text { PRINCIPLES OF } & \text { PRACTICES OF } \\ \text { INITIAL } & \text { COURSE } & \text { TEACHING } \\ \text { COMPETENCE } & \text { PLANNING } & \end{array}$

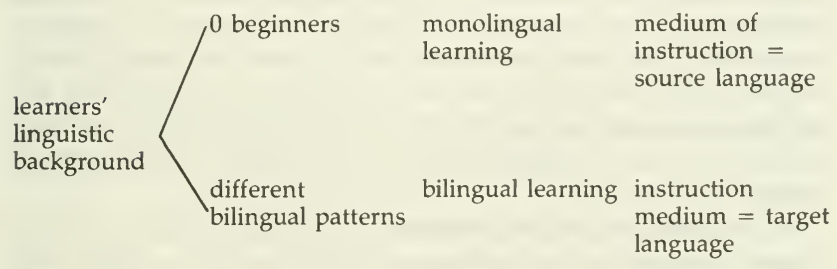

Fig. 3 Discrepancies in the learner's linguistic background 
Many foreign language teachers would agree, however much they would also regret it in others and themselves, that much of the explanation of the foreign language system and its functioning must rely on the learner's mother tongue: in other words the source language becomes the medium of instruction to teach the target language. In community language teaching the teacher may occasionally resort to sentences, comments and expressions in English (those typical of that repertoire of discipline and good behaviour in an English school); but it does not happen nearly as often that English is used as the medium to explain structures, functions and use of the community language in a course with young pupils, or even with older pupils who had previous instruction.

\section{Learner's association with the foreign/community culture.}

My second point concerns the association of the learner with the culture embodied and expressed by the target language. At the level of learner's initial competence, it seems to me that the assumption concerning the cultural association adopted by the course planners and teachers of foreign languages produces another and even greater discrepancy if transferred to the reality of community language learners. In fact in foreign language teaching the learner's initial association with the alien culture coincides with a totally monocultural starting point. The learner will start the course from a 0 beginner level in both language and culture; at its end, possibly in connection with an examination, in the best of circumstances some learners will have achieved a considerable competence in the foreign language. As for the cultural association there are not many chances that school instruction alone can involve the learner emotionally and cognitively beyond the knowledge of a literary repertoire, for the more capable scholars, and a set of images, symbols, sometimes stereotypes, for the less gifted linguist. The difference in a community language learning experience is quite remarkable: in fact for its learners the association with the life, traditions, values and customs embodied in that culture can be so strong, that we can often see it surviving for generations in individuals who have lost fluency in their language and have become totally assimilated, linguistically, in the majority group.

At the level of course planning, the total alienation of the learner towards the foreign language and its culture, implies that the course designer must operate a selection of those habits, atti- 
tudes, customs and beliefs, which make up, at instructional level, the corpus of the foreign culture. Despite the great efforts and energy of many dedicated teachers, some investigations seem to indicate that, from the collection of experiences and images of the foreign country and its culture, only a minority of pupils seem to retain intellectual curiosity and emotional participation. These frustrating results, compared with the hardship of the job, are not experienced in quite the same way by the community language teacher. In fact, whether the learner is more or less involved and whether s/he more or less associated her/himself with the habits and traditions within the family and the community circles, the language work can easily refer to a common set of interests, understanding and meanings peculiar to the life of the minority group and its neighbourhood.

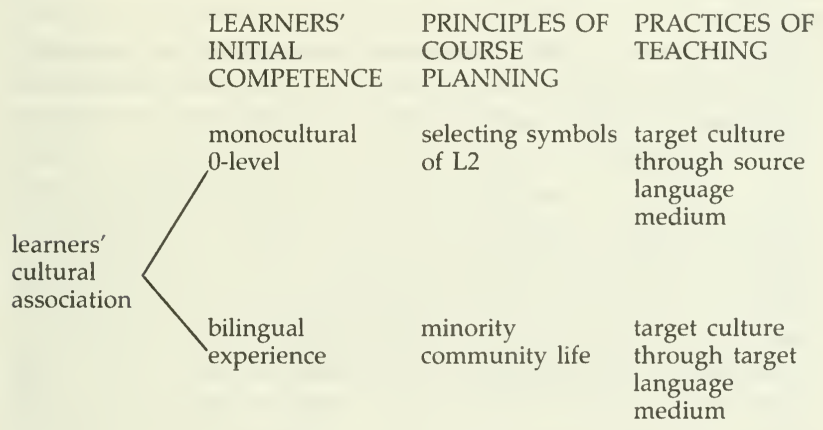

Fig. 4 Discrepancies in the learner's association with the target culture

In the practical teaching situation there is no need for the instructor to classify a repertoire of expressions and images of an alien culture to explain to its learners the social and cultural diversity between the two people, or to revert to their symbols to make those differences memorable and communicable to pupils. Moreover the questionable practice of using the pupils' mother tongue to explain the foreign culture is unthinkable.

So far, so good: the peculiarity of community language teaching seems to grant an advantage to their learning and their learners, if we compare their circumstances with those of a process of foreign language acquisition. But with the next points, certain questions 
which involve some easy decisions in the field of traditional foreign language teaching become considerable problems in the area of community language instruction and evaluation.

The target language.

The first of these points concerns the target language. In traditional foreign language teaching there are no decisions concerning the target language which can seriously affect the treatment of the learner's initial competence, or the planning of the course and the practices of its teaching. What I mean is that any decision concerning the "good models" of the target language does not have much to do with the teaching of it in a foreign course and to foreign learners. As far as the latter are concerned any model or variety or dialect chosen is equally alien; therefore once the course planner has made his decision as to what the "best" choice of language is (because socially prestigious, or economically marketable, or both) he simply has to draw consistently from his models during the teaching. A decision made by course planners, designers and evaluators in connection with a foreign language seldom, if ever, concerns the learners. But in community language learning this question is quite different. The problem of cultural discrepancy and linguistic distance between the two varieties or dialects of the same language, the one chosen for instruction in the classroom, the other that is actually spoken in the community, has enormous social, religious and emotional implications: these involve children who bring to school their natural language and who, as young people, will develop a delicate sensitivity towards their own language and cultural identity.

$\begin{array}{lll}\begin{array}{l}\text { LEARNERS' } \\ \text { INITIAL } \\ \text { COMPETENCE }\end{array} & \begin{array}{l}\text { PRINCIPLES OF } \\ \text { COURSE } \\ \text { PLANNING }\end{array} & \begin{array}{l}\text { PRACTICES OF } \\ \text { TEACHING }\end{array} \\ \begin{array}{l}0 \text { beginner } \\ \text { neutrality }\end{array} & \begin{array}{l}\text { learners alien to } \\ \text { all models }\end{array} & \begin{array}{l}\mathrm{L} 2=\text { foreign } \\ \text { language } \\ \text { acquisition }\end{array} \\ \begin{array}{l}\text { langet } \\ \text { learners' } \\ \text { negotiation }\end{array} & \begin{array}{l}\text { learners sensitive } \\ \text { to other models }\end{array} & \begin{array}{l}\text { strategies for } \mathrm{L} 2 \\ \text { teaching to } \\ \text { bilingual learners }\end{array}\end{array}$

Fig. 5 Discrepancies in the target language 
Any decision at the level of course planning, therefore, will have serious implications at the level of teaching practices, especially when the language of instruction and literacy is so diverse in structure and cultural meanings, to be, in actual fact, a language as alien to the learner almost as a foreign language.

\section{Evaluation of the learner's progress.}

The next point, also a problematic one, concerns the evaluation of the learning progress. Since the assessment of the learners' progress depends on our understanding of what is actually involved in the learning process, it has to be expected that even in community language learning, competence will be measured according to the ability to respect, or vice versa deviate, once the models have been identified from the norms of communication. In foreign language testing the measurement of this ability is not a problem. The process of second language acquisition by a monolingual has been meticulously described and quantified. Whether the teaching is based on grammar instruction or training in the communicative functions, from the initial stage of overwhelming dominance of the mother-tongue, the learner will be able to move further away from such dominance according to his/her progress in the internalisation of the foreign language system and his/her ability to practice its use. Therefore the role of the examiner is that of assessing and quantifying the phenomena of deviation from agreed models: these deviations, as we know, are produced by the natural interferences of a dominating language system (from the source language) upon the dominated system (of the target language). In community language learning, even after agreement is achieved as regard the target language for instruction, the question of deciding what are and what are not deviations from its models is far more acute than what is normally experienced by examiners of foreign languages.

Community language learners are likely to bring to the classroom a repertoire of structures and meaning which may be part of the community use of that language, but they considerably deviate from the original models in the mother-country. Naturally the less educational support that community and its speakers have received in the new country, the more frequent and substantial will be the phenomena of contacts and borrowings. 


\section{LEARNERS ${ }^{\prime} \quad$ PRINCIPLES OF PRACTICES OF INITIAL COURSE \\ COMPETENCE PLANNING}

$\begin{aligned} & \text { Evaluation of } \\ & \text { learners' } \\ & \text { progress }\end{aligned}$$\left\{\begin{array}{lll}\text { total L1 } \\ \text { dominance on L2 } & \begin{array}{l}\text { L1 interferences } \\ \text { on L2 = errors }\end{array} & \begin{array}{l}\text { rectifying } \\ \text { interferences }\end{array} \\ & \begin{array}{l}\text { distinguishing } \\ \text { partial L2 } \\ \text { dominance on L1 interferences } \\ \text { from contacts }\end{array} & \begin{array}{l}\text { interferences and } \\ \text { contacts = same } \\ \text { treatment? }\end{array}\end{array}\right.$

Fig. 6 Discrepancies in the evaluation of the learners' progress

At the level of initial competence this is bound to produce a first dilemma for teachers and course designers. When that repertoire of expressions, words, idioms is actually learnt from the body of the community language in the family and neighbourhood, should they be evaluated as phenomena of interference and deviation from correct norms of the original language, or as a development of the community language in the new linguistic environment? On the other hand, even learners of a community language, educated under the progressive dominance of English, will produce interferences and errors, in other words, individual deviations from the ordinary functions and use of the community language system. But many such interferences are already becoming part of the normal speech of a group or a community in an urban district; others have already become features of the language of the whole minority community throughout the country. These are no longer interferences, they are the results of language contacts: however, given the dynamic situation of language change, where can a line be drawn between the two, and, more important, who is to draw that line?

Design for a syllabus for instruction and evaluation.

The final point of my argument concerns the principles and criteria for the design of a syllabus for instruction and evaluation. Nowadays it is just impossible to refer to common patterns or criteria for second/foreign language syllabus design. So much has changed from the days when courses were largely, if not entirely, based on the teaching of the norms. In those days we were convinced that once the learner has mastered the set of rules govern- 
ing the second language system, he had all the information required to use that language effectively. Today many foreign language courses have successfully introduced new patterns of teaching language use, through functional/notional communicative syllabuses; and yet, many other teachers find it difficult to free themselves from the illusion that only the knowledge of rules can teach the correct use of a language.

I like the new communicative approach in language instruction and testing based on a functional syllabus. However, I think that it is important to realise its strengths as well as its limitations in different learning situations.

Firstly, the functional syllabus developed as a reaction against the claim that once the student has mastered the language system he/she has all the information he/she requires to use that language correctly. Since the rules of use are not the same in every language, it follows that the learner departing from 0 beginner level should be provided with a repertoire of functions equivalent to his/her needs, rather than information on the structure of the foreign language. But the situation of the monolingual learner with no contact with the foreign language outside the classroom is different from that of the community language learner. Not only does the bilingual learner have both contact and practice with the other language outside the classroom, but also his/her experience has developed more knowledge in the direction of language use than insight into the functioning of its structure. A further argument concerning initial competence runs on similar lines. Since the rules of language use are different in different languages, the risk with monolingual learners, taught about the structure of the language rather than its functions, is that no effective communication is created when the foreign speaker transfers use and translates literally from the source language to the target language. The risk of literal translation is not nearly so acute with bilingual learners as it is with learners of a foreign language: their competence in the community language may be limited and compartmentalised to certain functions or certain domains of use only; but since these are relevant to the life of the minority community it is most unlikely that their patterns of use and communication are learnt as transfers or translations from the rules governing the use of the other language. 


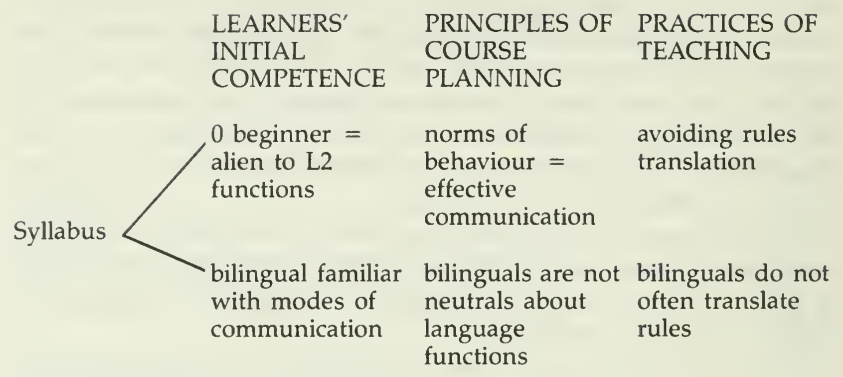

Fig. 7 Discrepancies between syllabuses for instruction and evaluation

There are also other arguments, relevant to course planning and teaching practices. In setting the objectives of a course one has to identify as a preliminary question the learners' needs. Subsequently, the identification of the target repertoire of functions becomes the linguistic knowledge to cover. If we choose, for example, a functional syllabus geared towards communication, the area of knowledge to cover will include a repertoire of expressions needed to enquire, introduce, invite, complain, apologise, advise etc. In order to do this, the course designer must first select which way of doing these things is appropriate to teach; and by selecting in this way, he will be imposing norms of behaviour on the pupils; norms which correspond to patterns of behaviour which combine social rules of interaction with heavy cultural and class connotations. Community language learners do not feel emotionally neutral about the nature and effect of these rules in the same way a foreign learner does about the models of social, cultural and personality styles in a language which is still largely alien to his/her experience.

\section{Oxford Polytechnic}

\section{SELECTED BIBLIOGRAPHY}

Baetens Beardsmore, H. (1982) Bilingualism: Basic Principles. Multilingual Matters, Clevedon, Avon.

Cummins, J.(1985) Bilingualism and Special Education. Multilingual Matters, Clevedon, Avon. 
Lambert, W.E. (1977) "The effects of bilingualism on the individual cognitive and sociocultural consequences." In P. Hornby (ed.), Bilingualism: Psychological, Social and Educational Implications, pp. 15-27. Academic Press, New York.

Linguistic Minorities Project (1984) The other Languages of England, Routledge Keagan and Paul.

Rosen, H. and Burgess T. (1980) Languages and Dialects of London School Children, Ward Lock Educational, London.

Skutnabb-Kangas, T. (1984) Bilingualism or not: the Education of Minorities, Multilingual Matters, Clevedon, Avon.

Swain, M. and Larkin (1983) Evaluating Bilingual Education: a Canadian Case-Study, Multilingual Matters, Clevedon, Avon.

Tosi, A. (1979) "Mother tongue teaching for the children of migrants," Language Teaching and Linguistics: Abstracts, 12 (4), 213-31.

. (1982a) "The development of Italian in the young ItaloAustralian bilingual child," Catholic Education Office of Victoria.

(1982b) "L'insegnamento dell'italiano alla seconda generazione dell'emigrazione." Paper from a Conference on "L'insegnamento dell'italiano come seconda lingua in Italia e all'estero" convened by Ministero degli Affari Esteri e Ministero della Pubblica Istruzione, Roma March 1982, published by Presidenza del Consiglio dei Ministri, Roma 1983.

(1982c) "Materials for mother tongue teaching in the context of second language learning; criteria for design and evaluation." Paper from a working party for the Third Assembly of the National Congress or Languages in Education (NCLE). In E. Reid (1984) Minority Community Languages in School. CILT, London, 45-82.

Oxford.

(1984) Immigration and Bilingual Education, Pergamon Press, 